\title{
Prediction of vaginal delivery with transperineal ultrasound in women induced with dinoprostone beyond 40 weeks of gestation
}

\author{
Hale Göksever Çelik ${ }^{1 *}$, Engin Çelik², Gökhan Yıldırım¹
}

\begin{abstract}
${ }^{1}$ Department of Obstetrics and Gynecology, Istanbul Kanuni Sultan Suleyman Training and Research Hospital, Saglik Bilimleri University, Istanbul/Turkey

${ }^{2}$ Department of Obstetrics and Gynecology, Faculty of Medicine, Istanbul University, Istanbul/Turkey
\end{abstract}

Received: 16 May 2018

Accepted: 23 June 2018

\section{*Correspondence: \\ Dr. Hale Göksever Çelik, \\ E-mail: hgoksever@yahoo.com}

Copyright: ( ) the author(s), publisher and licensee Medip Academy. This is an open-access article distributed under the terms of the Creative Commons Attribution Non-Commercial License, which permits unrestricted non-commercial use, distribution, and reproduction in any medium, provided the original work is properly cited.

\section{ABSTRACT}

Background: Digital cervical evaluation has been used to determine the likelihood of vaginal delivery which is considered by many women to be non-tolerable. Recently, transperineal ultrasound allowing direct visualization of the fetal skull has been using for the prediction of labor route. Authors aimed to study whether measurements on transperineal ultrasound are predictive for vaginal delivery in pregnant women induced with dinoprostone at 40.0 42.0 gestational weeks.

Methods: A total of 55 pregnant women at 40.0-42.0 gestational weeks were enrolled in this prospective observational study. All participated women were examined before the induction with dinoprostone to measure the head-perineum distance (HPD), the head-pubis distance and the angle of progression of fetal head (AOP).

Results: The greater AOP, the shorter HPD and the head-pubis distance were associated with vaginal delivery in the nulliparous women. The HPD and the head-pubis distance were shorter, whereas the AOP was greater in the multiparous women giving birth by vaginal route.

Conclusions: Transperineal ultrasound can be applied at the beginning of labor to predict whether vaginal delivery will occur or not. As shown in our study, the pregnant women with shorter HPD and wider AOP might have a high possibility to achieve vaginal delivery.

Keywords: Angle of progression of fetal head, Head-perineum distance, Head-pubis distance, Transperineal ultrasound, Vaginal delivery

\section{INTRODUCTION}

The rate of incidence of cesarean section is steadily increasing all over the world in recent years. The most important point is distinction between necessary and unnecessary cesarean sections. Because postponing the decision of cesarean section could cause undesirable results for the baby and the mother herself. On the other hand, unnecessary cesarean sections should be avoided because of its associated risks and complications.
Therefore, prediction of labor route has been assessed in studies to prevent these associated poor outcomes.

The Bishop score including digital assessment of cervical dilatation and effacement, fetal descent, the position and consistency of the cervix have been used to evaluate the labor progress and determine the likelihood of vaginal delivery. But all of them are subjective, inconsistent and associated with infections in recurrent vaginal examinations. Ultrasound was suggested to relate the level of the fetal head to the tip of maternal coccygeal 
bone in $1977 .{ }^{1}$ Transperineal ultrasound allowing direct visualization of the fetal skull, first described in the mid1990s, has been using widespread to evaluate the progress of labor in recent years. ${ }^{2}$ The head-perineum distance (HPD), the head-pubis distance and the angle of progression of the fetal head (AOP) can be evaluated with this simple, objective and non-invasive method. This examination is also applicable to all pregnant women with the low inter- and intra-observer variability.

In present study, authors aimed to study whether measurements on transperineal ultrasound such as AOP, HPD and the head-pubis distance are predictive for vaginal delivery in pregnant women induced with dinoprostone at 40.0-42.0 gestational weeks independent of the time required or the indication for cesarean section. The predictive values of each parameter on the way of delivery were also compared.

\section{METHODS}

A total of 55 pregnant women at 40.0-42.0 gestational weeks were enrolled in this prospective cohort study from August 2015 to July 2016. Our hospital's Ethics Committee (Istanbul, Turkey) approved our study which was in accordance with the Declaration of Helsinki (diary number 2015.14.7). All participated women were informed about the study and gave written informed consent.

The pregnant women at gestational age less than 40 weeks and the pregnant women having Bishop score higher than 5 were excluded from our study. The women with multiple pregnancy and previous uterine surgery and/or ruptured membranes or labor pain and the fetuses with the occiput posterior position and the presentation other than longitudinal cephalic presentation were also excluded.

Clinical and demographic characteristics of the patients were obtained from the patient. Gestational age was calculated from the last menstrual period and confirmed from the first trimester ultrasonographic measurement of the fetus. Body mass index (BMI) was calculated by measuring the weight and height of the patient on admission.

All participated women were examined before the admission to delivery unit in the supine position with flexed knees and hips and with an empty bladder. All ultrasonographic examinations were done by the same obstetrician using a Voluson 730 Expert with a $3.5 \mathrm{MHz}$ convex transabdominal probe. Transabdominal transducer was used to assess fetal biometric measurements, fetal position, habitus and placental location. Then this probe was placed between labia majora on the perineum covering with a glove to measure HPD, the head-pubis distance and AOP. The soft tissue on this area was compressed firmly with no discomfort for the woman. The HPD is the distance between the presenting point of fetal head and the perineum, whereas the head-pubis distance is the distance between the lower edge of the symphysis pubis and the fetal head. The AOP is calculated as an angle between the long axis of the symphysis pubis and the line in midsagittal plane passing through the lowest point of the symphysis pubis and tangent to the skull of the fetus as described by Barbara et al in $2009 .^{3}$

After the ultrasonographic evaluation, the status of cervix was assessed digitally by the obstetrician in the delivery unit. Bishop score is used to determine the stage of labor before and after the induction which is a quantitative means of describing the cervical status to decide the necessity of cervical ripening agents. The parameters in this score are cervical dilatation and effacement, the position and consistency of the cervix and the station of the fetal head. The pregnant women having Bishop score lower than 5 and were induced with dinoprostone (Propess ovule; Ferring Medical, Istanbul, Turkey). The obstetrician evaluating patients with ultrasonography was not involved during follow-up in delivery unit. The birth attendants were blinded about the ultrasonographic measurements of the patients. All patients were monitorized with non-stress test continuously. The obstetrician in the delivery unit decided on the delivery mode based on clinical assessment of the patient.

\section{Statistical analysis}

Data are demonstrated as mean \pm SD for normally distributed continuous variables and frequencies for categorical variables. Relevant parameters were examined separately by appropriate chi-square test or independent samples t-test depending on the parameter type and their relationship with the delivery method. Thresholds for the association of delivery route with ultrasonographic parameters were determined by initially using receiver operating characteristics (ROC) curves to ascertain the optimal cut-off for each analyte. When a significant cut-off value was observed, the sensitivity, specifity, positive likelihood ratio values were presented. While evaluating the area under the curve (AUC), a 5\% type-I error level was used to accept a statistically significant predictive value of the test variables. Statistical Package for Social Sciences (SPSS) for Windows version 22.0 (SPSS Inc., Chicago, IL, USA) was used for the analysis and two-sided $\mathrm{p}$ value of $<0.05$ was considered as significant.

\section{RESULTS}

A total of 55 pregnant women who met the criteria were enrolled in our study. The mean gestational age was $40.6 \pm 0.5$ weeks. The mean age of patients in the study was $29.9 \pm 6.8$ years and the mean BMI was $29.7 \pm 4.1$. The clinical and laboratory characteristics of the patients were summarized in Table 1. Most women in the study (32 patients, $58.2 \%$ ) were nulliparous. The mean duration of Propess ovule application was 11.9 hours. Transperineal 
ultrasound evaluation showed that the mean values for HPD, the head-pubis distance and AOP were $56.7 \mathrm{~mm}$, $48.8 \mathrm{~mm}$ and 112.3 degrees, respectively. The leading reason for cesarean section was obstructed labor followed by fetal distress and macrosomia. The leading reason for cesarean section was obstructed labor followed by fetal distress and macrosomia.

Table 1: Clinical and demographic characteristics of the patients.

\begin{tabular}{|l|l|}
\hline Characteristics & $\begin{array}{l}\text { Number }(\%) \text { or } \\
\text { mean } \pm \text { standard } \\
\text { deviation }\end{array}$ \\
\hline Maternal age & $29.9 \pm 6.8$ \\
\hline BMI $\left(\mathrm{kg} / \mathrm{m}^{2}\right)$ & $29.7 \pm 4.1$ \\
\hline Gravida & $2.2 \pm 1.5$ \\
\hline Parity & $32(58.2)$ \\
\hline 0 & $23(41.8)$ \\
\hline$\geq 1$ & $47(85.5)$ \\
\hline Maternal health problems & $8(14.5)$ \\
\hline Absent & $13.9 \pm 4.8$ \\
\hline Present & $40.6 \pm 0.5$ \\
\hline Weight gain (kg) & $56.7 \pm 15.0$ \\
\hline Gestational week (weeks) & $48.8 \pm 11.3$ \\
\hline Head-perineum distance (mm) & $112.3 \pm 16.1$ \\
\hline Head-pubis distance (mm) & $3.4 \pm 1.0$ \\
\hline $\begin{array}{l}\text { Angle of progeression of fetal } \\
\text { head (degree) }\end{array}$ & $11.9 \pm 7.9$ \\
\hline Bishop score before induction & $6.2 \pm 1.4$ \\
\hline Propess duration (hours) & $33(60)$ \\
\hline Bishop score after induction & $22(40)$ \\
\hline Birth way & $3403.4 \pm 373.3$ \\
\hline Vaginal birth & $3(13.6)$ \\
\hline Cesarean section & $8(36.4)$ \\
\hline Birth weight (grams) & $11(50)$ \\
\hline Indication for cesarean section & \\
\hline Macrosomia & \\
\hline Fetal distress & \\
\hline Obstructed labor & \\
\hline BMI, body mass index & \\
\hline
\end{tabular}

When the nulliparous women were analyzed according to delivery route, the mean Propess duration was significantly shorter and the mean Bishop score after induction was significantly higher in the vaginal delivery group ( $\mathrm{p}$ values 0.028 and 0.001 ). The shorter HPD and head-pubis distance and the greater AOP were also associated with vaginal delivery in the nulliparous women ( $\mathrm{p}$ values $0.006,0.045$ and 0.28 , respectively) (Table 2).

In the multiparous women, the mean age and gravidity were significantly lower in the vaginal delivery group ( $\mathrm{p}$ values 0.027 and 0.037). The mean BMI and the gestational week were also significantly lower in the vaginal delivery group ( $\mathrm{p}$ values 0.027 and 0.028 ). The mean Bishop score after induction was significantly higher in the vaginal delivery group $(\mathrm{p}=0.038)$.
Table 2: Comparison of nulliparous women according to delivery route.

\begin{tabular}{|llll|}
\hline Characteristics & $\begin{array}{l}\text { Vaginal } \\
\text { birth } \\
(\mathbf{n}=14)\end{array}$ & $\begin{array}{l}\text { Cesarean } \\
\text { section } \\
(\mathbf{n}=18)\end{array}$ & p \\
\hline Age & $25.8 \pm 5.3$ & $27.3 \pm 5.6$ & 0.451 \\
\hline BMI $\left(\mathrm{kg} / \mathrm{m}^{2}\right)$ & $28.21 \pm 4.60$ & $28.77 \pm 3.64$ & 0.704 \\
\hline $\begin{array}{l}\text { Weight gain } \\
\text { (kg) }\end{array}$ & $15.3 \pm 5.3$ & $14.4 \pm 5.2$ & 0.636 \\
\hline $\begin{array}{l}\text { Gestational } \\
\text { weeks }\end{array}$ & $40.9 \pm 0.3$ & $41.0 \pm 0.3$ & 0.501 \\
\hline $\begin{array}{l}\text { Head- } \\
\text { perineum } \\
\text { distance (mm) }\end{array}$ & $54.38 \pm 12.83$ & $56.95 \pm 16.57$ & 0.006 \\
\hline $\begin{array}{l}\text { Head-pubis } \\
\text { distance (mm) }\end{array}$ & $43.48 \pm 11.29$ & $46.08 \pm 8.33$ & 0.045 \\
\hline $\begin{array}{l}\text { Angle of } \\
\text { progression of } \\
\text { fetal head }\end{array}$ & $118.1 \pm 15.8$ & $112.4 \pm 13.7$ & 0.028 \\
\hline $\begin{array}{l}\text { Bishop score } \\
\text { before } \\
\text { induction }\end{array}$ & $2.9 \pm 1.1$ & $3.3 \pm 1.2$ & 0.350 \\
\hline $\begin{array}{l}\text { Propess } \\
\text { duration } \\
\text { (hours) }\end{array}$ & $12.8 \pm 4.8$ & $15.9 \pm 9.8$ & 0.028 \\
\hline $\begin{array}{l}\text { Bishop score } \\
\text { after induction }\end{array}$ & $7.3 \pm 0.8$ & $5.0 \pm 1.3$ & 0.001 \\
\hline $\begin{array}{l}\text { Birth weight } \\
\text { (grams) }\end{array}$ & $3282 \pm 241$ & $3346 \pm 305$ & 0.526 \\
\hline \begin{tabular}{l} 
BMI, body mass index \\
\hline
\end{tabular} & & \\
\hline
\end{tabular}

BMI, body mass index

Table 3: Comparison of multiparous women according to delivery route.

\begin{tabular}{|llll|}
\hline Characteristics & $\begin{array}{l}\text { Vaginal } \\
\text { birth } \\
(\mathrm{n}=19)\end{array}$ & $\begin{array}{l}\text { Cesarean } \\
\text { section } \\
(\mathrm{n}=4)\end{array}$ & $\mathrm{p}$ \\
\hline Age & $29.8 \pm 5.3$ & $33.2 \pm 5.6$ & 0.027 \\
\hline Gravida & $3.2 \pm 1.1$ & $4.7 \pm 2.1$ & 0.037 \\
\hline BMI $(\mathrm{kg} / \mathrm{m} 2)$ & $30.67 \pm 3.28$ & $35.05 \pm 3.69$ & 0.027 \\
\hline $\begin{array}{l}\text { Weight gain }(\mathrm{kg}) \\
\begin{array}{l}\text { Gestational } \\
\text { weeks }\end{array}\end{array}$ & $12.8 \pm 4.3$ & $11.5 \pm 3.1$ & 0.561 \\
\hline $\begin{array}{l}\text { Head-perineum } \\
\text { distance (mm) }\end{array}$ & $50.6 \pm 0.6$ & $41.4 \pm .5$ & 0.028 \\
\hline $\begin{array}{l}\text { Head-pubis } \\
\text { distance (mm) }\end{array}$ & $53.98 \pm 12.46$ & $54.95 \pm 5.87$ & 0.882 \\
\hline $\begin{array}{l}\text { Angle of } \\
\text { progression of } \\
\text { fetal head }\end{array}$ & $110.5 \pm 17.2$ & $99.9 \pm 19.5$ & 0.028 \\
\hline $\begin{array}{l}\text { Bishop score } \\
\text { before induction }\end{array}$ & $3.6 \pm 0.8$ & $4.0 \pm 0.0$ & 0.294 \\
\hline $\begin{array}{l}\text { Propess duration } \\
\text { (hours) }\end{array}$ & $8.6 \pm 6.8$ & $7.4 \pm 4.7$ & 0.732 \\
\hline $\begin{array}{l}\text { Bishop score } \\
\text { after induction }\end{array}$ & $6.9 \pm 0.8$ & $5.7 \pm 1.5$ & 0.038 \\
\hline $\begin{array}{l}\text { Birth weight } \\
\text { (grams) }\end{array}$ & $3478 \pm 383$ & $3721 \pm 769$ & 0.348 \\
\hline $\begin{array}{l}\text { BMI, body mass } \\
\text { Bnting }\end{array}$ & & & 0.006 \\
\hline
\end{tabular}

BMI, body mass index 
The shorter HPD and the greater AOP were associated with vaginal delivery in multiparous women ( $\mathrm{p}$ values 0.006 and 0.028) (Table 3). Area under curves for the prediction of vaginal delivery were $48 \%$ (95\% confidence interval (CI), 28-69\%) and 62\% (95\% CI, 42-82\%) for fetal HPD and AOP in nulliparous women, whereas AUCs for the prediction of vaginal delivery were $51 \%$ (95\% confidence interval $(\mathrm{CI}), 29-73 \%)$ and $75 \%(95 \%$ CI, 43-100\%) for fetal HPD and AOP in multiparous women (Figure 1).
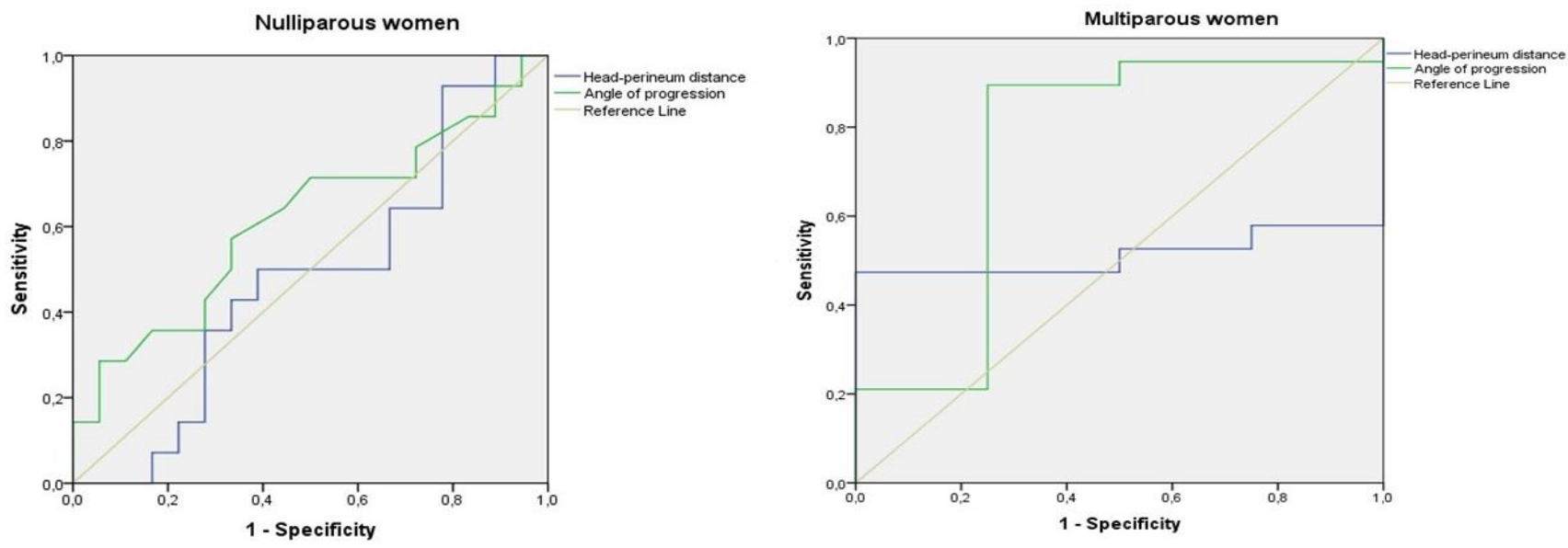

Figure 1: The ROC curve between the measurements on transperineal ultrasound and the prediction of vaginal birth in nulliparous and multiparous women.

Vaginal delivery occurred with cut-off values for $\mathrm{HPD} \leq 54.5 \mathrm{~mm}$ and $\mathrm{AOP} \geq 115.5^{\circ}$ in nulliparous women, whereas vaginal delivery occurred with cut-off values for $\mathrm{HPD} \leq 58.5 \mathrm{~mm}$ and $\mathrm{AOP} \geq 93.2^{\circ}$ in multiparous women. If these values were compared with each other, the most helpful parameter for prediction of vaginal delivery was AOP in all women.

\section{DISCUSSION}

The decision for cesarean section at the right time to allow appropriate interventions about the mother and the baby is important. Accurate prediction of vaginal delivery especially in nulliparous women is very difficult. Because the digital cervical examination is unreliable, subjective and inconsistent and prone to high number of errors in the evaluation between the obstetricians. Therefore, transperineal ultrasound which is objective and more comfortable for pregnant women has been suggested to predict for vaginal delivery.

Authors studied the utility of transperineal ultrasound for the prediction of vaginal delivery on the pregnant women who induced with dinoprostone at 40.0-42.0 gestational weeks. Induction stimulates the uterine contractions before the spontaneous onset of the labor. Some studies found that induction increased the rate of cesarean section compared with the spontaneous labor. ${ }^{4}$ The response to induction was examined with the Bishop score for many years which does not have a direct relationship with the vaginal delivery. ${ }^{5,6}$ Recently, transperineal ultrasound has been preferred for this purpose evaluating the relationship between fetal head and maternal pelvic bones.

Eggebo et al found the association between the transperineal ultrasound findings in the first stage of labor and the likelihood of vaginal delivery. ${ }^{2}$ Because digital examination of cervical dilatation and transperineal ultrasound measurements are compatible with each other and transperineal ultrasound is less invasive and has a very good repeatability for women. ${ }^{7,8}$

Authors used the following measurements on transperineal ultrasound to detect whether it is useful to predict vaginal delivery: HPD, head-pubis distance and AOP. The angle greater than $120^{\circ}-126^{\circ}$ was associated with vaginal delivery in many publications. ${ }^{3,9}$ In present study, authors found that the shorter HPD and the wider AOP correlated with the higher the possibility of vaginal delivery both in nulliparous and multiparous women. Sainz et al showed that women with the greater AOP gave vacuum-assisted delivery more easily. If AOP was $\leq 120^{\circ}$, they observed that the delivery required more than 4 vacuum pulls with an $85 \%$ probability. ${ }^{10}$ Same researchers also studied the prediction of success of vaginal delivery in vacuum extraction attempt in another study and found that AOP is an important measurement associated with successful vaginal delivery. ${ }^{11}$

A group of researchers studied about the prediction of vaginal delivery with the subpubic arch angle on transperineal ultrasound, but they could not find a 
relationship between them and they commented that there were several factors other than bony pelvis in the birth mechanism. ${ }^{1}$ Some studies compared the two-dimensional and three-dimensional transperineal ultrasound methods to predict the delivery mode and they found no practical clinical differences between them, but both of them seemed to perform better than digital cervical examination. However, two-dimensional transperineal ultrasound was cheaper than three-dimensional transperineal ultrasound. ${ }^{13}$

The most correlated parameter with the fetal head station and the prediction of vaginal delivery was AOP on transperineal ultrasound confirmed by open magnetic resonance imaging. ${ }^{14}$ Chan et al proposed the model including AOP and HPD together with cervical dilatation to assess the progress of labor in a new partogram in future. Because the parameters on transperineal ultrasound showing the best agreement with fetal head descent and digital examinations were AOP and HPD. ${ }^{15,16}$ Cervical digital examination may be only needed when dilatation is advanced. ${ }^{17}$

According to present results, nulliparous women with $\mathrm{HPD} \leq 54.5 \mathrm{~mm}$ or $\mathrm{AOP} \geq 115.5^{\circ}$ and multiparous women with $\mathrm{HPD} \leq 58.5 \mathrm{~mm}$ or $\mathrm{AOP} \geq 93.2^{\circ}$ might have a high possibility to achieve vaginal delivery. If narrower AOP or greater HPD are encountered, doctors should be careful about the low chance of successful vaginal delivery.

Present results showed that AOP was the most valuable parameter and provided the most accurate prediction for vaginal delivery as in many other studies. Because the other parameters may vary with many factors such as BMI of the patient. ${ }^{18}$ Another study evaluating the predictive value of HPD, cervical length and Bishop score in vaginal delivery found that HPD had a greater value than that of cervical length and Bishop score. ${ }^{19}$

The superiority of our study to others is to investigate of the utility of transperineal ultrasound for prediction of vaginal delivery in women with low Bishop score induced with dinoprostone beyond 40 weeks of gestation. Present limitation is the small number of cases and further studies will be carried out supporting our results.

\section{CONCLUSION}

As a conclusion, there is no still objective method to predict the likelihood of vaginal delivery. We believe that transperineal ultrasound will be used as an alternative to traditional clinical examinations for evaluation of women during admission to delivery units, because it is significantly better tolerated and has a predictive value for vaginal delivery. But further studies should be carried out to prove its utility in the prediction of vaginal delivery.

\section{Funding: No funding sources}

Conflict of interest: None declared

Ethical approval: The study was approved by the Institutional Ethics Committee

\section{REFERENCES}

1. Lewin D, Sadoul G, Beuret T. Measuring the height of a cephalic presentation: an objective assessment of station. Eur J Obstet Gynecol Reprod Biol. 1977;7:36972.

2. Eggebo TM, Wilhelm-Benartzi C, Hassan WA, Hassan WA, Usman S, Salvesen KA, et al. A model to predict vaginal delivery in nulliparous women based on maternal characteristics and intrapartum ultrasound. Am J Obstet Gynecol. 2015;213:362. e1-6.

3. Barbera AF, Pombar X, Peragino G, Lezotte DC, Hobbins JC. A new method to assess fetal head descent in labor with transperineal ultrasound. Ultrasound Obstet Gynecol. 2009;33:313-19.

4. Shaikh F, Shaikh S, Shaikh N. Outcome of primigravida with high head at term. J Pak Med Assos. 2014;64:1012-14.

5. Bahadori F, Ayatollahi H, Naghavi-Behzad M, Khalkhali H, Naseri Z. Predicting factors on cervical ripening and response to induction in women pregnant over 37 weeks. Med Ultrason. 2013;15:191-8.

6. Meijer-Hoogeveen M, Roos C, Arabin B, Stoutenbeek $\mathrm{P}$, Visser GH. Transvaginal ultrasound measurement of cervical length in the supine and upright positions versus Bishop score in predicting successful induction of labor at term. Ulrasound Obstet Gynecol. 2009;33:213-20.

7. Benediktsdottir S, Eggebo TM, Salvesen KA. Agreement between transperineal ultrasound measurements and digital examinations of cervical dilatation during labor. BMC Pregn Childbirth. 2015;15:273.

8. Hennemann J, Kennes LN, Maass N, Najjari L. Evaluation of established and new reference lines for the standardization of transperineal ultrasound. Ultrasound Obstet Gynecol. 2014;44:610-6.

9. Ciaciura-Jarno M, Cnota W, Wojtowicz D, Niesluchowska-Hoxha A, Ruci A, Kierach R, et al. Evaluation of selected ultrasonography parameters in the second stage of labor in prediction mode of delivery. Ginekol Pol. 2016;87:448-53.

10. Sainz JA, Borrero C, Fernandez-Palacin A, et al. Intrapartum transperineal ultrasound as a predictor of instrumentation difficulty with vacuum-assisted delivery in primiparous women. J Matern Fetal Neonatal Med. 2015;28:2041-47.

11. Sainz JA, Borrero C, Aquise A, Aquise A, Valdivieso $\mathrm{P}$, Pastor L, et al. Utility of intrapartum transperineal ultrasound to predict cases of failure in vacuum extraction attempt and need of cesarean section to complete delivery. J Matern Fetal Neonatal Med. 2016;29:1348-52.

12. Albrich SB, Shek K, Krahn U, Dietz HP. Measurement of subpubic arch angle by three-dimensional transperineal ultrasound and impact on vaginal delivery. Ultrasound Obstet Gynecol. 2015;46:496-500.

13. Torkildsen EA, Salvesen KA, Eggebo TM. Prediction of delivery mode with transperineal ultrasound in 
women with prolonged first stage of labor. Ultrasound Obstet Gynecol. 2011;37:702-8.

14. Bamberg C, Scheuermann S, Slowinski T, Dückelmann AM, Vogt M, Nguyen-Dobinsky TN, et al. Relationship between fetal head station established using an open magnetic resonance imaging scanner and the angle of progression determined by transperineal ultrasound. Ultrasound Obstet Gynecol. 2011;37:712-16.

15. Chan YT, Ng VK, Yung WK, Lo TK, Leung WC, Lau WL. Relationship between intraprtum transperineal ultrasound measurement of angle of progression and head-perineum distance with correlation to conventional clinical parameters of labor progress and time to delivery. J Matern Fetal Neonatal Med. 2015;28:1476-81.

16. Marsoosi V, Pirjani R, Mansouri B, Eslamian L, Jamal A, Heidari R, et al. Role of 'angle of progression' in prediction of delivery mode. J Obstet Gynecol Res. 2015;41:1693-9.
17. Yuce T, Kalafat E, Koc A. Transperineal ultrasonography for labor management: accuracy and reliability. Acta Obstet Gynecol Scand. 2015;94:760-5.

18. Eggebo TM, Hassan WA, Salvesen KA, Lindtjorn E, Lees CC. Sonographic prediction of vaginal delivery in prolonged labor: a two-center study. Ultrasound Obstet Gynecol. 2014;43:195-201.

19. Alvarez-Colomo C, Gobernado-Tejedor JA. The validity of ultrasonography in predicting the outcomes of labour induction. Arch Gynecol Obstet. 2016;293:311-16.

Cite this article as: Çelik HG, Çelik E, Yıldırım G. Prediction of vaginal delivery with transperineal ultrasound in women induced with dinoprostone beyond 40 weeks of gestation. Int J Reprod Contracept Obstet Gynecol 2018;7:2998-3003. 